\title{
Real Patient and its Virtual Twin: Application of Quantitative Systems Toxicology Modelling in the Cardiac Safety Assessment of Citalopram
}

\author{
Nikunjkumar Patel, ${ }^{1,2}$ Barbara Wiśniowska, ${ }^{2}$ Masoud Jamei, ${ }^{1}$ and Sebastian Polak ${ }^{1,2,3}$
}

Received 3 August 2017; accepted 16 October 2017; published online 27 November 2017

\begin{abstract}
A quantitative systems toxicology (QST) model for citalopram was established to simulate, in silico, a 'virtual twin' of a real patient to predict the occurrence of cardiotoxic events previously reported in patients under various clinical conditions. The QST model considers the effects of citalopram and its most notable electrophysiologically active primary (desmethylcitalopram) and secondary (didesmethylcitalopram) metabolites, on cardiac electrophysiology. The in vitro cardiac ion channel current inhibition data was coupled with the biophysically detailed model of human cardiac electrophysiology to investigate the impact of (i) the inhibition of multiple ion currents $\left(\mathrm{I}_{\mathrm{Kr}}, \mathrm{I}_{\mathrm{Ks}}, \mathrm{I}_{\mathrm{CaL}}\right)$; (ii) the inclusion of metabolites in the QST model; and (iii) unbound or total plasma as the operating drug concentration, in predicting clinically observed QT prolongation. The inclusion of multiple ion channel current inhibition and metabolites in the simulation with unbound plasma citalopram concentration provided the lowest prediction error. The predictive performance of the model was verified with three additional therapeutic and supra-therapeutic drug exposure clinical cases. The results indicate that considering only the hERG ion channel inhibition of only the parent drug is potentially misleading, and the inclusion of active metabolite data and the influence of other ion channel currents should be considered to improve the prediction of potential cardiac toxicity. Mechanistic modelling can help bridge the gaps existing in the quantitative translation from preclinical cardiac safety assessment to clinical toxicology. Moreover, this study shows that the QST models, in combination with appropriate drug and systems parameters, can pave the way towards personalised safety assessment.
\end{abstract}

KEY WORDS: Citalopram; Cardiotoxicity; QT prolongation; Cardiac safety simulator; Simcyp; hERG; Personalised medicine; Quantitative systems toxicology; Virtual twin.

\section{INTRODUCTION}

Citalopram (CT) is one of the most widely prescribed antidepressant drugs (1). It has been linked with cardiac toxicity (especially at higher doses) resulting in the US FDA advocating restrictions on the maximum daily dose in 2011 (2) and further restrictions to the recommended dosage in special populations in 2012 (3). Cardiac safety concerns associated with CT were documented prior to the 2011 FDA warning. In fact, the clinical development of the drug was halted in the

Electronic supplementary material The online version of this article (https://doi.org/10.1208/s12248-017-0155-8) contains supplementary material, which is available to authorized users.

\footnotetext{
${ }^{1}$ Simcyp Limited, a Certara Company, Blades Enterprise Centre, John Street, Sheffield, S2 4SU, UK.

${ }^{2}$ Faculty of Pharmacy, Jagiellonian University Medical College, Kraków, Poland.

${ }^{3}$ To whom correspondence should be addressed. (e-mail: Sebastian.polak@certara.com)
}

1980s due to the sudden unexplained deaths of dogs who were administered CT as part of high dose toxicity studies (4). Later, as part of a detailed evaluation, the torsadogenic potential of the secondary metabolite of CT, didesmethylcitalopram (DDCT), was investigated. Following CT dosing, the metabolite DDCT was found at high levels in dogs but not in other species studied, including humans due to species-specific metabolic differences (4). There is evidence suggesting that CT inhibits multiple cardiac ion currents: $\mathrm{I}_{\mathrm{Kr}}$ (rapidly activating delayed rectifier potassium channel current) $(5), \mathrm{I}_{\mathrm{Ks}}$ (slowly activating delayed rectifier potassium channel current) (5), and $\mathrm{I}_{\mathrm{CaL}}$ (late calcium channel current) $(6,7)$; it is also suspected to interfere with additional ionic channels and currents (8). Furthermore, the primary metabolite desmethylcitalopram (DCT) and secondary metabolite (DDCT) are also known to inhibit $\mathrm{I}_{\mathrm{Kr}}$ and $\mathrm{I}_{\mathrm{Ks}}$ currents (5). DDCT is only detectable in human blood following the administration of high CT doses. The peak in the level of DDCT typically occurs several hours after the ingestion of high doses of CT. The cardiotoxicity is also observed much 
later after ingestion of high doses of CT which can be attributed to the delayed formation and accumulation of DDCT following high CT dose administration (9). However DDCT is not the only toxicity factor involved, since high concentrations of $\mathrm{CT}$ can also affect cardiac function by modifying the electrophysiology of the heart via the central nervous system (CNS). This complex interplay of the parent drug, its metabolites, and the inhibitory effect on multiple cardiac ion channels may all contribute to the continued debate on the cardiac safety associated with CT (3,10-12). Until recently, torsadogenicity assessments were typically focused on the inhibition of the cardiac $\mathrm{I}_{\mathrm{Kr}}$ current occurring at the level of the hERG channel (encoded by the human ether-a-go-go gene) (13-16). Over the last few years, the comprehensive in vitro proarrythmia assay (CiPA) initiative has been advocating the in vitro assessment of multiple cardiac ion currents and the estimation of the combined effect of multiple ionic channel inhibition using cardiomyocyte cell-based quantitative systems models $(17,18)$. However, the primary focus of the CiPA has been on the parent drug, specifically at the single cardiac cell level (19). Assessment of the QT prolongation liability of a drug based only on the parent drug and the hERG-centric evaluations could be misleading since many drugs such as CT affect not only $\mathrm{I}_{\mathrm{Kr}}$ but also other ionic currents and may have electrophysiologically active metabolites $(14,20)$. Testing all probable hypotheses in clinical and/or animal studies may be practically, ethically, and economically unfeasible (4). Therefore, modelling and simulation methods can complement experimental studies and reduce and/or refine the number of performed experiments. In this study, we assessed the ability of the biophysically detailed models of cardiac electrophysiology, parameterised with in vitro cardiac ion channel inhibition data, to predict the QT prolongation observed clinically at various exposure levels and under varied clinical scenarios. We also investigated the following scientific questions to explain the observed QT prolongation with CT administration at therapeutic and supra-therapeutic concentrations (up to 100-fold higher): (i) is the parent drug (CT) exclusively responsible for the observed QT prolongation? (ii) is the $\mathrm{I}_{\mathrm{Kr}}$ (hERG) inhibition activity by all chemical moieties (CT, DCT, and DDCT) the only ion current that causes the observed clinical cardiotoxic events? (iii) what is the operating concentration of drug and metabolites to drive the cardiac response-unbound plasma or total plasma concentration? Most of the systems toxicology models are established and verified based on the average response of a population or a trend. Using quantitative system modelling, here we assessed the potential of actually simulating the 'virtual twin' (21) of a real patient, considering their physiology and specific clinical conditions (drug exposure, heart rate, etc.). The resulting cardiotoxic event was then predicted for a given individual under specified conditions in silico. The meaning of a 'virtual twin' could be different in clinical literature (22), so for our study, we refer to a 'virtual twin' as an in silico model with systems (physiology) parameters mimicking an individual patient under given clinical circumstances that allows simulation of the clinical response/outcome of interest for that patient. We simulated four clinical scenarios from therapeutic dose to 70-fold overdose situations and compared the simulation results with clinically observed QT prolongation or TdP. Utilisation of quantitative systems models to simulate absorption, distribution, and elimination of a single drug or combination of drugs, generally referred to as physiologically based pharmacokinetics (PBPK) models, have already been well established in defining or refining appropriate dosage recommendations in regulatory submissions (23-26). However, utilisation of such a quantitative systems approach to simulate therapeutic response or toxicity events is not widely explored, probably due to the limited availability of sufficiently verified systems toxicology models and/or the availability of suitable input and quantitative systems (physiology) data to parameterise the model. Here we employed a QST model to predict drug cardiotoxicity, namely QT prolongation, after therapeutic and supra-therapeutic dosing of CT. Verification of the predictive performance of the model was done against four different clinical datasets of varying demographics and physiological conditions.

\section{MATERIAL AND METHODS}

The ten Tusscher (2006) ventricular cardiomyocyte cell model (27) was used to form a one-dimensional (1D) string mimicking the cross-section of the ventricular wall (as implemented within the Cardiac Safety Simulator (CSS) version 2.0 (13)) for simulating pseudo-electrocardiogram (pseudoECG) traces. It is termed pseudoECG since it is based only on the string of ventricular cells, hence missing atrial activity, characterised by the $\mathrm{P}$ wave on a clinical electrocardiogram (ECG) signal. The CSS is a platform combining electrophysiologically based models of the human left ventricular cardiomyocytes and a database of human physiological, genotypic, and demographical data. The CSS platform facilitates the generation of a virtual realistic population variability in cardiac physiology during simulations (Fig. IA) $(28,29)$. The CSS platform is the first of its kind accounting for circadian variability in heart rate and plasma concentration of electrolytes $\mathrm{Na}^{+}, \mathrm{K}^{+}$, and $\mathrm{Ca}^{2+}$ using covariate models derived from actual clinical data $(30,31)$. Epidemiological models which take into account the effect of gender and age on ventricular heart wall thickness, cardiomyocyte volume/capacitance, and sarcoplasmic reticulum are also built into the CSS platform (Fig. IB) (28). A 1D string of cells (ventricular wall thickness) paced at the endocardial side used the 50:30:20 distribution of the endo-, mid-, and epicardium cells, respectively, with an average diffusion coefficient of $0.0016 \mathrm{~cm}^{2} / \mathrm{ms}$. The forward Euler method was used to integrate the model equations with a space step and a time step of $0.01 \mathrm{~mm}$ and $0.01 \mathrm{~ms}$, respectively. Total simulation time was set to $10,000 \mathrm{~ms}$, and during the simulation, multiple beats were added at the beginning to reach a steady state and then withdrawn from the final analysis to assure stability and to avoid computation bias.

A thorough literature search was conducted to identify the reported clinical cases of TdP associated with citalopram in which there were no known physiological diseases (e.g., cirrhosis) or medications (e.g., metabolic drug-drug interactions) that could alter the disposition of CT. We used all the cases we could find from public literature where both plasma concentration of at least parent and time-matching QT 
measurement was available along with patient characteristics. As the aim was to mimic an individual subject, we did not use population mean or average apart from the TQT trial from FDA for therapeutic dose of $20 \mathrm{mg}$. To avoid bias, we intended to find cases where maximum possible data on pharmacokinetics and patient electrophysiology information was measured in the clinic. We conducted literature search and review via PubMed, Google Scholar, and citation within some review articles and could identify three clinical case reports which presented the occurrence of actual cardiotoxic events following the ingestion of CT where drug concentrations, patient demographics and heart rate parameters, and clinical conditions (e.g. plasma electrolyte concentrations) were measured for us to closely mimic the real clinical scenario (30-32). Most of these reports were overdose situations, hence to verify the QST model, QT prolongation at a therapeutic dose of $20 \mathrm{mg}$ was also simulated and compared with corresponding clinical data although matching set of measured drug concentration, QT prolongation, and heart rate was not available from single study at the therapeutic dose level of $20 \mathrm{mg}$. We simulated a $20-\mathrm{mg}$ dose to assess the applicability of the model not only at overdose situation but also at lowest clinical dose to include the wider range of exposure and effect relationship. Additional heart wall physiology parameters which are not commonly measured in routine clinical trials such as ventricular heart wall thickness, and cardiomyocyte size were either calculated from age and gender of the patient using known covariate models or assumed based on known values of that parameter for a healthy Caucasian population. Finally, four clinical reports containing measured plasma drug concentration and QT prolongation data (with CT doses ranging from $20 \mathrm{mg}$ to $>$ $1400 \mathrm{mg}$ (>70-fold dose range) and the 100-fold range of maximum observed plasma CT concentrations) were chosen for the simulations (2,30-33). The reported clinical settings, in terms of the number of subjects and their demographic and physiological parameters, were replicated as precisely as possible in the simulations. With the exception of the Ji et al. study (33), the metabolite concentrations were not typically reported. When not reported, the metabolite concentrations were estimated from the reported parent drug (CT) concentration using known parent/metabolite ratios calculated from the Ji et al. study (33) - 4 and 36 for the CT/DCT and CT/DDCT ratios, respectively. Free plasma concentrations were estimated from plasma protein binding information obtained for the parent and its metabolites. The unbound plasma fraction $\left(f_{\mathrm{u}}\right)$ was estimated using the quantitative structure activity relation (QSAR) model implemented within the Simcyp Simulator V14.0 (Sheffield, UK) since experimentally measured values were not available for the metabolites $(34,35)$. The QSAR model for $f_{\mathrm{u}}$ in Simcyp is based upon the equations published by Lobell and Sivarajah (36), modified to explicitly account for a fraction of compound ionised at physiological $\mathrm{pH}$ considering $\mathrm{pKa}$ of the compound. The QSAR-based $f_{\mathrm{u}}$ of CT (0.23) was very similar to the reported value of approximately 0.2 (37). As CT, DCT, and DDCT are very similar in chemical structure, we assumed that the QSAR model can also reliably predict the CT metabolite (DCT and DDCT) $f_{\mathrm{u}}$ values. We therefore used the predicted plasma protein binding for both metabolites $\operatorname{DCT}\left(f_{\mathrm{u}}=0.38\right)$ and $\operatorname{DDCT}\left(f_{\mathrm{u}}=0.52\right)$ in the absence of experimentally measured values. Although CT, DCT, and DDCT may appear structurally very similar, the removal of methyl groups lead to significant difference in compound lipophilicity $(\log \mathrm{P})$ and ionisation $(\mathrm{pKa})$ which are structural properties used in the QSAR equation to predict $f_{\mathrm{u}}$. Reduction in lipophilicity and increase in polarity of chemical lead to reduction in binding to plasma proteins resulting to increase in predicted value of $f_{\mathrm{u}}$ from CT to DCT to DDCT. The plasma concentrations of CT, DCT, and DDCT for each of the four clinical scenarios are reported in Table I.

In vitro ion channel inhibition activity data for CT, DCT, and DDCT for $\mathrm{I}_{\mathrm{Kr}}, \mathrm{I}_{\mathrm{Ks}}$, and $\mathrm{I}_{\mathrm{CaL}}$ currents were extracted from the literature (Table II). Drug concentration-dependent reduction of the maximal conductance of a particular ionic current was calculated directly in the CSS platform according to Eq. 1.

$$
\text { Inhibition factor }=\frac{1}{1+\left(\mathrm{IC}_{50} / \text { Concentration }\left(\frac{\mu m o l}{\mathrm{~L}}\right)\right)^{n}}
$$

The simple additive effect model (38) of all active moieties was assumed during simulations to calculate the total inhibition with the use of in vitro inhibition parameters of individual moieties provided in Table II.

We ran five simulations with different settings to assess which scenario is most likely to explain the observed QT prolongation. The tested scenarios are as follows:

SIM 1: Free plasma concentrations of all moieties (CT, DCT, and DDCT) and multiple ion channel inhibition information $\left(\mathrm{I}_{\mathrm{Kr}}, \mathrm{I}_{\mathrm{Ks}}\right.$, and $\left.\mathrm{I}_{\mathrm{CaL}}\right)$ for all moieties

SIM 2: Total plasma concentrations of all moieties and multiple ion channel inhibition information for all moieties

SIM 3: Free plasma concentrations of all moieties but considering $\mathrm{I}_{\mathrm{Kr}}$ inhibition only

SIM 4: Free plasma concentration of CT only to drive the response and using only $\mathrm{I}_{\mathrm{Kr}}$ inhibition data for $\mathrm{CT}$

SIM 5: Free plasma concentration of CT only to drive the response and using $\mathrm{I}_{\mathrm{Kr}}, \mathrm{I}_{\mathrm{Ks}}$, and $\mathrm{I}_{\mathrm{CaL}}$ inhibition data for CT.

The overdose clinical case reports (30-32) refer to the patients under intensive hospital care due to experiencing a life-threatening cardiac event after CT ingestion. Hence, many parameters were monitored such as heart rate, plasma $\mathrm{K}^{+}, \mathrm{Na}^{+}$, and $\mathrm{Ca}^{2+}$ ion concentrations in addition to the actual drug concentration. Further details of the simulated scenarios are provided below in a case by case format. The physiology parameter inputs used in the simulations for each of the four cases are described in Table III.

\section{Study-Specific Data Used in the Simulations}

Case I. From the case report of a CT overdose of a 46year-old female subject (with the intention to commit suicide) published by Unterecker et al. (2012), drug exposure and clinical ECG data were obtained at multiple time points after drug ingestion (32). The demography (age and gender) and 


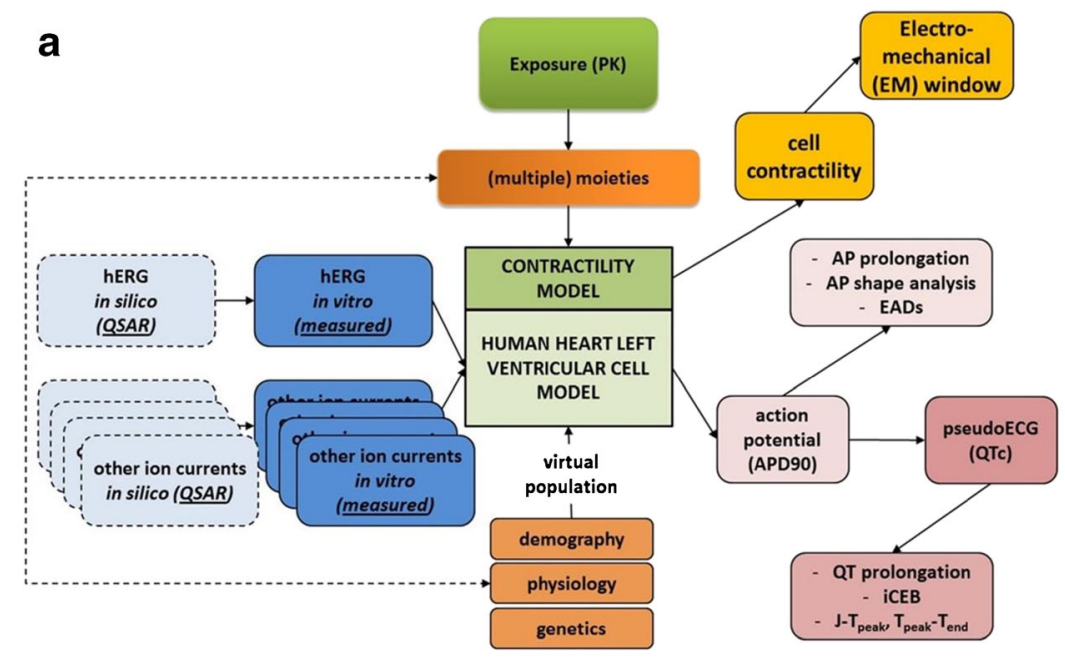

b
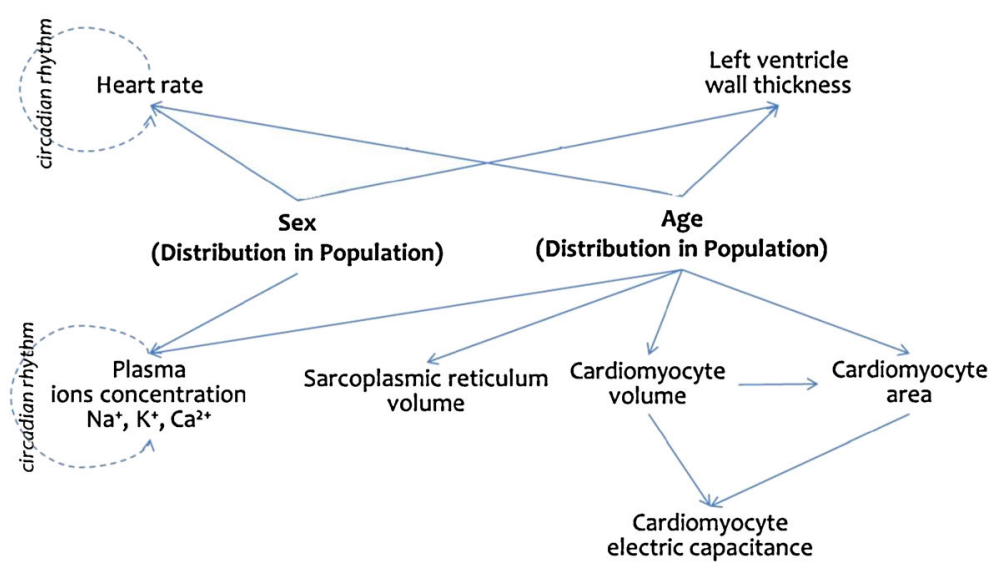

Fig. I. a Framework of Cardiac Safety Simulation (CSS) platform. b Physiological covariate relationship and circadian models incorporated in the CSS platform

physiology (heart rate, plasma $\mathrm{K}^{+}, \mathrm{Na}^{+}, \mathrm{Ca}^{2+}$ ion concentrations) reported in the clinical case study were simulated using the reported CT plasma drug concentrations and estimated metabolite concentrations. In other words, a 'virtual twin' of the actual subject was built in silico and used to assess the observed QT prolongation. Many parameters defining the subject physiology were measured; however, there were some (e.g. heart wall thickness and conductance)

Table I. Plasma Concentrations of CT, DCT, and DDCT Used During the Simulation

\begin{tabular}{|c|c|c|c|c|c|c|c|c|c|}
\hline \multirow{2}{*}{$\begin{array}{l}\text { Clinical } \\
\text { scenario }\end{array}$} & \multirow{2}{*}{ Clinical study } & \multirow{2}{*}{$\begin{array}{l}\text { Exposure } \\
\text { ID }^{a}\end{array}$} & \multirow{2}{*}{$\begin{array}{l}\text { Time post } \\
\text { dose }\end{array}$} & \multicolumn{3}{|c|}{ Total plasma concentration $(\mu \mathrm{M})$} & \multicolumn{3}{|c|}{ Free plasma concentration $(\mu \mathrm{M})$} \\
\hline & & & & CT (rep) & DCT (calc) & DDCT (calc) & CT (rep) & DCT (calc) & DDCT (calc) \\
\hline \multirow[t]{5}{*}{ Case I } & \multirow[t]{5}{*}{ Unterecker et al. 2012 (32) } & S1E1 & Day 2 & 3.795 & 0.949 & 0.105 & 0.873 & 0.361 & 0.055 \\
\hline & & S1E2 & Day 3 & 2.842 & 0.711 & 0.079 & 0.654 & 0.270 & 0.041 \\
\hline & & S1E3 & Day 4 & 2.454 & 0.613 & 0.068 & 0.564 & 0.233 & 0.035 \\
\hline & & S1E4 & Day 6 & 1.514 & 0.378 & 0.042 & 0.348 & 0.144 & 0.022 \\
\hline & & S1E5 & Day 23 & 0 & 0 & 0 & 0 & 0 & 0 \\
\hline Case II & Tarabar et al. 2008 (31) & S2E1 & $33 \mathrm{~h}$ & 1.470 & 0.368 & 0.041 & 0.338 & 0.140 & 0.021 \\
\hline \multirow[t]{3}{*}{ Case III } & \multirow[t]{3}{*}{ Liotier and Coudoré 2011 (30) } & S3E1 & $7 \mathrm{~h}^{b}$ & 18.126 & 4.532 & 0.504 & 4.169 & 1.722 & 0.262 \\
\hline & & S3E2 & $21 \mathrm{~h}^{b}$ & 7.460 & 1.865 & 0.207 & 1.716 & 0.709 & 0.108 \\
\hline & & S3E3 & $45 \mathrm{~h}^{b}$ & 7.398 & 1.850 & 0.206 & 1.702 & 0.703 & 0.107 \\
\hline Case IV & Ji et al. 2014 and FDA $(3,33)$ & S4E1 & Day 1 & 0.195 & 0.051 & 0.005 & 0.045 & 0.019 & 0.002 \\
\hline
\end{tabular}

rep reported in the respective clinical trial, calc calculated as described in the main text, $C T$ citalopram, $D C T$ desmethylcitalopram, $D D C T$ didesmethylcitalopram, $I D$ identification

${ }^{a}$ Each set of drug and metabolite exposure points were simulated and given an ID for clarity in the discussion in the main text

${ }^{b}$ The time reported is post hospitalisation as the exact time of drug administration was not available in the study 
Table II. Cardiac Ion Channel Inhibition Data Used in the Simulations and its Source

\begin{tabular}{lllll}
\hline Moiety & \multicolumn{4}{l}{$\mathrm{IC}_{50}$ in $\mu \mathrm{M}$ (Hill equation coefficient) } \\
\cline { 2 - 5 } & $\mathrm{I}_{\mathrm{Kr}}$ & $\mathrm{I}_{\mathrm{Ks}}$ & $\mathrm{I}_{\mathrm{CaL}}$ & Reference \\
\hline $\mathrm{CT}$ & $1.1(0.83)$ & $1059^{a}(1)$ & $60.28(1)^{b}$ & $(5,7)$ \\
DCT & $2.1(0.89)$ & $3956^{a}(1)$ & $\mathrm{NA}$ & $(5)$ \\
DDCT & $2.7(0.92)$ & $0.28(0.88)$ & $\mathrm{NA}$ & $(5)$ \\
\hline
\end{tabular}

$N A$ the data was not available, hence it was assumed negligible in all simulations; $C T$ citalopram; DCT desmethylcitalopram; $D D C T$ didesmethylcitalopram; $I_{K r}, I_{K s}, I_{C a L}$ represent rapidly activating delayed rectifier potassium channel current, slowly activating delayed rectifier potassium channel current, and late calcium channel current, respectively; $I C_{50}$ half maximal inhibitory concentration

${ }^{a}$ Calculated $\mathrm{IC}_{50}$ within the CSS platform based on \%inhibition versus concentration profile reported in the reference

${ }^{b}$ Hill coefficient was not reported in the study, hence assumed to be 1

which were not available, so we calculated those unavailable parameters using the covariate models of a healthy Caucasian population physiology from age and gender of a patient (28). The values of the heart rate and plasma ion concentrations reported in the clinical studies were either the average values recorded over a period of a few seconds or minutes or were a specific value at the time of measurement, both of which are known to have inter-occasion variability. To account for such uncertainty, we simulated each drug concentration effect, for an individual subject, five times considering known 'withinsubject variability' in those parameters implemented within the CSS platform.

Case II. Tarabar et al. (2008) reported the case of a 36year-old woman who ingested 50 tablets of $20 \mathrm{mg}$ CT (approximately 1000-mg dose) with wine (31). We used the clinically measured drug concentrations, estimated metabolite concentrations, and physiological parameters (such as heart rate and plasma ion concentrations) as inputs to the model. Each concentration time point was simulated five times. The model does not take into account the influence of alcohol on the heart rate mechanistically; however, the measured heart rate values were used as input data which implicitly considers the effect of alcohol on the heart rate in our simulations.

Case III. In the Liotier and Coudoré 2011 study, a 54year-old female subject ingested an unknown number of CT tablets that demonstrated a 100-fold higher plasma drug concentration as compared to the typical plasma drug concentrations reported with a therapeutic dose level (20 mg) (30). She also suffered from hypokalemia. We included all known clinical parameters (age, gender, plasma $\mathrm{K}^{+}, \mathrm{Na}^{+}, \mathrm{Ca}^{2+}$ ion concentrations, heart rate, etc.) in our simulations to mimic the clinical scenario as precisely as possible. Each concentration time point was simulated five times to factor in uncertainty or inherent variability in those physiological parameters as described earlier.

Case IV. QT prolongation information for a 20-mg CT dose was obtained from the US FDA assessment report (2) which, to the best of our knowledge, is not published in the peer-reviewed journals. The plasma concentrations of CT, DCT, or DDCT were not reported in the FDA assessment report. Hence, we used the plasma drug concentrations reported in another informative clinical study conducted with a 20-mg CT dose to simulate the effect at a 20-mg dose level (33) where CT, DCT, and DDCT concentrations were reported. Moreover, the FDA letter only reported $\Delta \mathrm{QTc}$ (QT prolongation by the drug in comparison to placebo), and the correction method for heart rate was not clearly specified. Hence, we calculated $\Delta$ QTc from our simulation results (QT prolongation triggered by the drug in comparison to QT at zero drug concentration under the same physiological conditions) using the Fridericia correction method (QTcF). As clinical data for case IV is a population mean value rather than the response of particular patient, we simulated 16 virtual healthy Caucasian individuals ( $50 \%$ females) based on default covariate models implemented in the CSS platform and compared the population mean values of $\Delta \mathrm{QTcF}$ generated from the simulated trial to the observed clinical trial.

CT is known to modify the electrophysiology of the heart via the CNS, an effect that could contribute to the observed QT prolongation. We did not explicitly model the impact of the CNS-mediated cardiac effect of CT in this current work. However, we used the clinically measured heart rate values at different drug concentration time points implicitly considering the effect of CT on the heart rate via the CNS modulation.

The simulated QT prolongation observed with the above described four cases (cases I-IV) was then compared with the clinically measured QT prolongation.

\section{RESULTS}

The simulated QT and QTc for all four clinical cases (cases I-IV) and ten simulated exposure data points for five different scenarios (SIMs 1-5) along with corresponding clinical observations are summarised in Table IV. Absolute error (AE) in prediction [Abs (OBS-PRED)] and average absolute error (AAE) are reported for each case where the observed data allowed to accurately calculate the errors. For all cases (cases I-IV) and exposure levels, the SIM 1 simulation scenario setting has consistently provided the lowest prediction error with respect to clinically reported QT prolongation. We tested all simulation scenarios (SIMs 1-5) for case I and case II to establish our hypothesis and then simulated only the SIM 1 and SIM 2 settings for the remaining two cases (case III and case IV) to verify the hypothesis. Since case I is the richest in terms of data points, the average absolute error (AAE) was also reported for easier comparison of various settings (SIMs 1-5).

The predicted QTc for all five time points of case I with different simulation settings (SIMs 1-5) are shown along with clinical QTc in Fig. II. It is evident from Fig. II and Table IV that when parent and both metabolites effect on all three cardiac ion currents were accounted for with unbound plasma concentration as operating concentration to drive response, the predictions were closest to the clinical data. The actual QT was not reported in case IV; hence, the average $\Delta \mathrm{QTcF}$ of the simulated population was compared 
Table III. Physiology (Systems) Parameters Input to the QST Model in the Simulation Cases I-IV

\begin{tabular}{|c|c|c|c|c|c|}
\hline $\begin{array}{l}\text { Physiology input } \\
\text { parameters }\end{array}$ & $\begin{array}{l}\text { Case I } \\
\text { simulated } \\
\text { (clinical) }\end{array}$ & $\begin{array}{l}\text { Case II } \\
\text { simulated } \\
\text { (clinical) }\end{array}$ & $\begin{array}{l}\text { Case III } \\
\text { simulated } \\
\text { (clinical) }\end{array}$ & $\begin{array}{l}\text { Case IV } \\
\text { s i m u la t e d } \\
\text { (clinical) }\end{array}$ & Reference \\
\hline Gender & $\begin{array}{l}\text { F e m a le } \\
\text { (female) }\end{array}$ & $\begin{array}{l}\text { F e m a l e } \\
\text { (female) }\end{array}$ & $\begin{array}{l}\text { F e m a } 1 \text { e } \\
\text { (female) }\end{array}$ & $\begin{array}{l}9 \text { females; } 9 \\
\text { male (NR) }\end{array}$ & As reported/assumed \\
\hline Age (years) & $46(46)$ & $36(36)$ & $54(54)$ & $27 \pm 7(\mathrm{NR})$ & As reported/assumed \\
\hline $\begin{array}{l}\text { Cardiomyocyte area } \\
\left(\mu \mathrm{m}^{2}\right)\end{array}$ & $\begin{array}{l}4342 \pm \\
1360(\mathrm{NR})\end{array}$ & $\begin{array}{l}2936 \pm 919 \\
(\mathrm{NR})\end{array}$ & $\begin{array}{l}5963 \pm \\
1882(\mathrm{NR})\end{array}$ & $\begin{array}{l}2096 \pm 806 \\
(\mathrm{NR})\end{array}$ & $\begin{array}{l}\text { Calculated with known covariate model from age and gender } \\
\text { (29) }\end{array}$ \\
\hline $\begin{array}{l}\text { Left ventricular wall } \\
\text { thickness }(\mathrm{cm})\end{array}$ & $1.45(\mathrm{NR})$ & $1.36(\mathrm{NR})$ & $1.54(\mathrm{NR})$ & $\begin{array}{l}1.28 \pm 0.13 \\
(\mathrm{NR})\end{array}$ & Calculated with known covariate model from age (29) \\
\hline Cell capacitance $(\mathrm{pF})$ & $\begin{array}{l}115 \pm 36 \\
(\mathrm{NR})\end{array}$ & $\begin{array}{l}78 \pm 24 \\
(\mathrm{NR})\end{array}$ & $\begin{array}{l}158 \pm 50 \\
(\mathrm{NR})\end{array}$ & $56 \pm 21(\mathrm{NR})$ & $\begin{array}{l}\text { Calculated with known covariate model from age and gender } \\
\text { (28) }\end{array}$ \\
\hline Heart rate & $\begin{array}{l}\text { A } \mathrm{s} \\
\text { reported }\end{array}$ & $\begin{array}{l}\text { A s } \\
\text { reported }\end{array}$ & $\begin{array}{l}\text { A s } \\
\text { reported }\end{array}$ & $\begin{array}{l}\text { Calculated } \\
\text { (NR) }\end{array}$ & $\begin{array}{l}\text { Reported or calculated if not reported, with known covariate } \\
\text { model from age, gender and time of day (39) }\end{array}$ \\
\hline Plasma $\mathrm{K}^{+}[\mathrm{mM}]$ & $\begin{array}{l}4.05 \pm 0.4 \\
\text { (normal) }\end{array}$ & $\begin{array}{l}3.1 \pm 0.3 \\
(3.1)\end{array}$ & $\begin{array}{l}2.9 \pm 0.3 \\
(2.9)\end{array}$ & $\begin{array}{l}4.15 \pm 0.8 \\
(\mathrm{NR})\end{array}$ & $\begin{array}{l}\text { Calculated from covariate model with age, gender and time of } \\
\text { day (40) }\end{array}$ \\
\hline Plasma $\mathrm{Na}^{+}[\mathrm{mM}]$ & $\begin{array}{l}135 \pm 1.9 \\
\text { (normal) }\end{array}$ & $\begin{array}{l}134 \pm 2 \\
(133)\end{array}$ & $\begin{array}{l}135 \pm 1.9 \\
(\mathrm{NR})\end{array}$ & $140 \pm 4(\mathrm{NR})$ & \\
\hline Plasma $\mathrm{Ca}^{++}[\mathrm{mM}]$ & $\begin{array}{l}2.2 \pm 0.1 \\
\text { (normal) }\end{array}$ & $\begin{array}{l}2.25 \pm 0.1 \\
(2.3)\end{array}$ & $\begin{array}{l}2.2 \pm 0.1 \\
(\mathrm{NR})\end{array}$ & $2.4 \pm 0.3(\mathrm{NR})$ & \\
\hline
\end{tabular}

$N R$ not reported in the clinical study report

with the population mean $\Delta$ QTc reported in the clinical study report to calculate the prediction error. Although all important assumptions are declared in the 'Discussion' section and information about the model inputs and how they were obtained are described in the 'Material and Methods' section, detailed simulation output report files are provided as supplementary material for an interested user to explore further raw simulated psedoECG traces, additional output parameters, and all input parameters used during simulations. Supplementary materials 1, 2, 3, and 4 represent the simulation output reports of S1E1, S2E1, S3E1, and S4E1 simulations.

\section{DISCUSSION}

Case I records the highest number of clinical measurements (i.e. drug concentration with matching QT and RR interval for four different time points after CT ingestion) providing the most comprehensive scenario for verifying our hypotheses (32). We ran five different simulations (SIM 1SIM 5) with various combinations of responsible moieties, ion channels, and operating concentrations as specified in the 'Material and Methods' section. The results are shown in Fig. II and Table IV. The simulated results showed that when free plasma concentrations of all three entities (CT, DCT, and DDCT) and multiple ion channel interactions were considered (SIM 1), the simulated QTcB (QT interval corrected for heart rate by Bazett's correction) (41) showed the lowest AAE (Table IV). We used Bazett's correction method to match the reported QTc in the clinical study report. The heart rate (as RR interval) is provided in Table IV; hence, an interested reader can apply any other heart rate correction formulae, e.g. Fridericia, and compare the results; however, we do not anticipate the choice of correction formulae to influence our conclusions. When total plasma concentrations were used as the operating concentration with all moieties, and all ion channel interactions were considered (SIM 2), the QT prolongation was over-predicted. PseudoECG traces of SIM 1 and SIM 2 scenarios compared to placebo (zero drug and metabolite concentrations) over a period of $10 \mathrm{~s}$ are shown in Fig. III. QT interval from the ECG signals was automatically calculated by an inbuilt algorithm within the CSS platform and reported in Table IV.

When we used free plasma concentration as the operating concentration and all moieties with only hERG inhibition (SIM 3), the model under-predicted the effect; hence, it appears that the inclusion of the $\mathrm{I}_{\mathrm{Ks}}$ current is important. When we neglected the effect of metabolites by simulating only the parent (CT) concentration with either only $\mathrm{I}_{\mathrm{Kr}}$ (SIM 4) or with multiple ion channels (SIM 5), we under-predicted the observed QTcB indicating the significant contribution of metabolites (especially that of DDCT which is clinically important as a potent $\mathrm{I}_{\mathrm{Ks}}$ current inhibitor). Thus, the simulation result of case $\mathrm{I}$ indicates that consideration of metabolites, together with parent drug and multiple ion channels, is important in the accurate prediction of QT prolongation after CT ingestion (Table IV, Fig. II). However, it is worth noting that the established model has several key assumptions:

- A 1D model of the ventricular heart wall is sufficient to simulate the clinical ECG signal which is a three-dimensional phenomenon in reality.

- $\quad$ The parent to metabolite ratios obtained at a 20mg CT dose level are valid at supra-therapeutic dose levels. Studies by Unterecker et al. (32) and Liotier and Coudoré (30) showed a linear elimination phase of CT plasma concentration profiles at supratherapeutic doses, probably indicating non-saturable clearance at the studied dose ranges.

- The combined effect of parent and metabolite on various ion channel currents is additive. 
Table IV. Observed and Predicted QT Interval or Prolongation (in Milliseconds) After Administration of Various Doses of CT

\begin{tabular}{|c|c|c|c|c|c|c|c|c|c|c|c|c|c|c|}
\hline \multirow[t]{5}{*}{ Case } & \multirow{5}{*}{$\begin{array}{l}\text { Exposure } \\
\text { ID }\end{array}$} & \multicolumn{3}{|c|}{ Observed } & \multicolumn{10}{|c|}{ Predicted } \\
\hline & & & & & \multicolumn{4}{|c|}{ All moieties multiple channels } & \multicolumn{6}{|c|}{ Free Plasma Concentration } \\
\hline & & & & & \multirow{2}{*}{\multicolumn{2}{|c|}{$\begin{array}{l}\begin{array}{l}\text { Free } \\
\text { plasma }\end{array} \\
\text { SIM } 1\end{array}$}} & \multirow{2}{*}{\multicolumn{2}{|c|}{$\begin{array}{l}\begin{array}{l}\text { Total } \\
\text { plasma }\end{array} \\
\text { SIM } 2\end{array}$}} & \multirow{2}{*}{\multicolumn{2}{|c|}{$\begin{array}{l}\begin{array}{l}\text { All moieties } \\
\text { only } \mathrm{I}_{\mathrm{Kr}}\end{array} \\
\text { SIM } 3\end{array}$}} & \multirow{2}{*}{\multicolumn{2}{|c|}{$\begin{array}{l}\text { Only CT } \\
\text { only } \mathrm{I}_{\mathrm{Kr}} \\
\text { SIM } 4\end{array}$}} & \multicolumn{2}{|c|}{$\begin{array}{l}\text { Only CT } \\
\text { multiple channels }\end{array}$} \\
\hline & & & & & & & & & & & & & SIM 5 & \\
\hline & & $\begin{array}{l}\text { QT } \\
(\mathrm{ms})\end{array}$ & $\begin{array}{l}\mathrm{RR} \\
(\mathrm{s})\end{array}$ & $\begin{array}{l}\text { QTcB } \\
(\mathrm{ms})\end{array}$ & $\begin{array}{l}\text { QTcB } \\
(\mathrm{ms})\end{array}$ & $\begin{array}{l}\mathrm{AE} \\
(\mathrm{ms})\end{array}$ & $\begin{array}{l}\text { QTcB } \\
(\mathrm{ms})\end{array}$ & $\begin{array}{l}\mathrm{AE} \\
(\mathrm{ms})\end{array}$ & $\begin{array}{l}\text { QTcB } \\
(\mathrm{ms})\end{array}$ & $\begin{array}{l}\mathrm{AE} \\
(\mathrm{ms})\end{array}$ & $\begin{array}{l}\text { QTcB } \\
(\mathrm{ms})\end{array}$ & $\begin{array}{l}\mathrm{AE} \\
(\mathrm{ms})\end{array}$ & $\begin{array}{l}\text { QTcB } \\
(\mathrm{ms})\end{array}$ & $\begin{array}{l}\mathrm{AE} \\
(\mathrm{ms})\end{array}$ \\
\hline \multirow[t]{5}{*}{ Case $\mathrm{I}^{a}$} & S1E1 & 460 & 0.74 & 535 & 538 & 3 & 618 & 83 & 499 & 36 & 481 & 54 & 484 & 51 \\
\hline & S1E2 & 460 & 0.83 & 505 & 495 & 10 & 576 & 71 & 465 & 40 & 452 & 53 & 455 & 50 \\
\hline & S1E3 & 440 & 0.74 & 511 & 513 & 2 & 589 & 78 & 486 & 25 & 473 & 38 & 475 & 36 \\
\hline & S1E4 & 420 & 0.78 & 476 & 483 & 7 & 536 & 60 & 413 & 63 & 404 & 72 & 404 & 72 \\
\hline & S1E5 & 380 & 0.78 & 430 & 438 & 8 & 438 & 8 & 438 & 8 & 438 & 8 & 438 & 8 \\
\hline $\mathrm{AAE}(\mathrm{ms})$ & & & & & & 6 & & 60 & & 34.4 & & 45 & & 43.4 \\
\hline Case II $^{a}$ & S2E1 & NA & $0.4-0.6$ & $572-600$ & 597 & 11 & 624 & 38 & 577 & 9 & 566 & 20 & 569 & 17 \\
\hline \multirow[t]{3}{*}{ Case III $^{a}$} & S3E1 & 440 & 0.531 & 604 & $\mathrm{CNC}$ & & $\mathrm{CNC}$ & & & & & & & \\
\hline & S3E2 & 600 & 0.8 & 671 & 641 & 30 & 737 & 66 & & & & & & \\
\hline & S3E3 & 420 & 0.428 & 642 & $\mathrm{CNC}$ & & $\mathrm{CNC}$ & & & & & & & \\
\hline Case $\mathrm{IV}^{b, c}$ & S4E1 & NA & NA & 8.5 & 9.53 & 1.03 & 21.93 & 13.43 & & & & & & \\
\hline
\end{tabular}

$C N C$ cannot calculate due to a metamorphic ECG trace which can be inferred as arrhythmia as in the actual clinical study, $N A$ not available, $A E$ is the absolute error in prediction, $A A E$ is the average absolute error for a given case study, $R R$ is the time interval in seconds between two consecutive R waves on the ECG trace which also represents heart rate, $Q T c B$ is the QT interval in ms corrected for heart rate by Bazzett's formulae, ID identification, $C T$ citalopram, SIMs 1-5 simulations 1-5

${ }^{a}$ Predicted is an average of five simulations for a given individual (see supplementary material for inter-occasion variability generated in heart rate and plasma electrolyte concentrations and simulated pseudoECG)

${ }^{b}$ Average value of a population in clinical and simulation studies

${ }^{c}$ Prolongation in QTcF interval (in ms) from drug as compared to placebo ( $\Delta \mathrm{QTcF}$ )

- In the absence of measured/estimated heart tissue concentrations, the CT plasma concentrations are considered the effective drug exposure driving the cardiac response, while other reports suggest that the heart tissue concentration is a better surrogate drug exposure driving the cardiac response (42-44).

- Plasma protein binding is non-saturable for the studied drug concentrations.

With several assumptions and uncertainties described, to build more confidence in the model, we employed a further three clinical scenarios to see if the same model can also explain other observed clinical outcomes. We tested the model using data collated from other clinical studies; QT prolongation at a therapeutic dose of $20 \mathrm{mg}$ and two more cardiotoxicity case reports describing a CT overdose $(30,31)$. The results consistently indicated that considering all moieties (CT, DCT, and DDCT) and multiple ion channel interactions with free plasma concentration as the operating concentration is crucial in the prediction of an accurate cardiotoxicity profile of citalopram at therapeutic and supra-therapeutic doses (Table IV). The pseudoECG trace simulated for the Liotier and Coudoré 2011 study (case III) was morphologically erratic, and the signal analysis module implemented within the CSS platform was not able to calculate the QT interval using the default automated QT interval calculation algorithm [Fig. IV]. We hypothesise that the erratic pseudoECG signal was the effect of a combination of high concentrations of active moieties, rapid heart rate, and hypokalemia (30). The observation of clinical ECG traces in the clinical study report appears to show deviation from the standard rhythm of an ECG signal. However, the clinical study reported a QT interval probably from the manual reading of the observed QT interval taken from the erratic ECG profile. The simulations were able to predict the erratic ECG signal of this clinical scenario although comparison of the QT interval was not possible since the automatic calculation of QT interval in the model could not be performed due to the erratic and non-physiological simulated ECG traces (Fig. IV). It could be read manually from the predicted native ECG traces; however, we did not perform a manual interpretation of the pseudoECG signal into the QT interval.

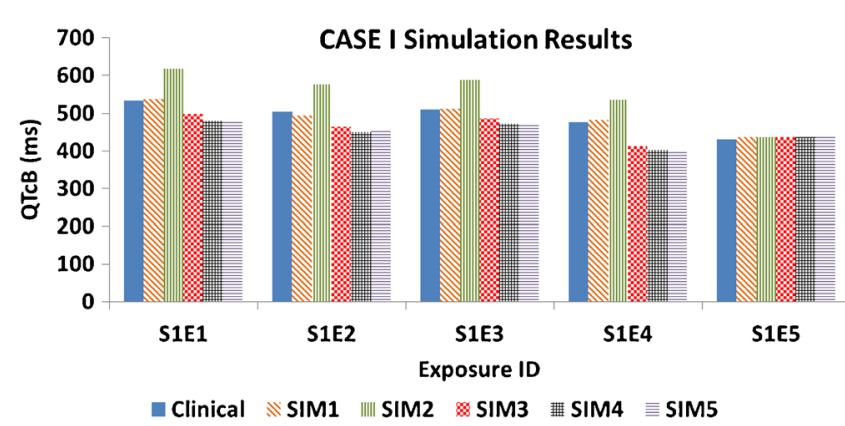

Fig. II. Comparison of simulated QTcB interval with different simulation settings (SIM 1-SIM 5) at five different exposure levels (S1E1-S1E5) of case I 


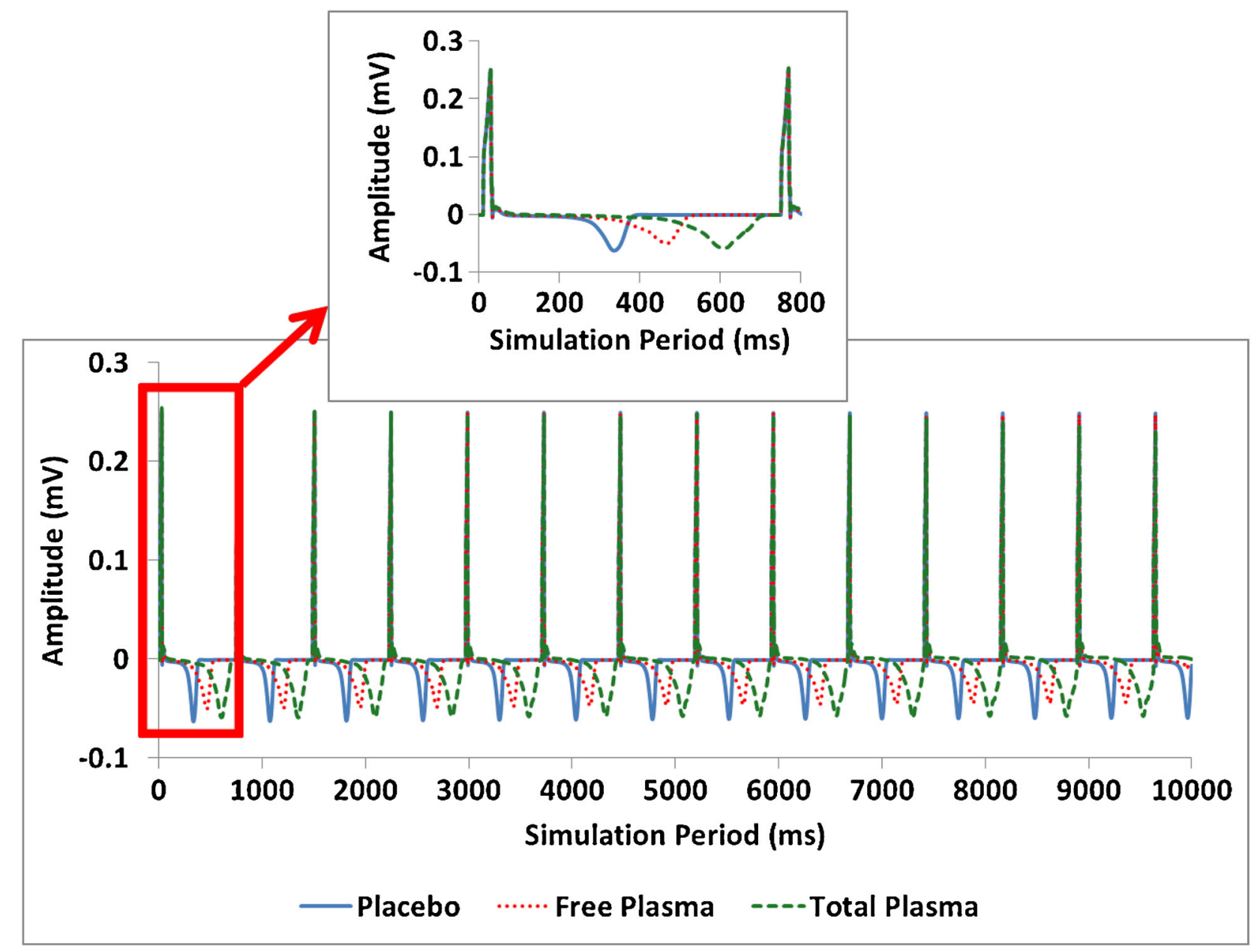

Fig. III. PseudoECG trace over a 10-s period for S1E1 exposure level with free plasma (SIM 1) or total plasma (SIM 2) concentrations

We established the systems cardiotoxicity model for CT and verified the predictive performance of the model against four different clinical studies at different dose levels and physiological conditions to improve confidence in our findings. We identified a simulation scenario that consistently explained the observed QT prolongations, at all dose levels, as the plausible mechanism of the QT prolongation of citalopram. Mechanistic models are useful tools for assessing hypotheses and understanding mechanisms of toxicity which are otherwise difficult or practically impossible to study in vivo. For example, it is difficult to only study the effect of $\mathrm{CT}$ in vivo since the drug is converted to the metabolite DCT via multiple metabolic pathways and then rapidly transformed to DDCT; hence, all three moieties exist and exert their effects simultaneously, blocking multiple ion channels. In contrast, accurately parameterised and sufficiently qualified physiologically based models can be used to conduct various simulations to investigate 'what-if?' scenarios for understanding or establishing the underlying mechanisms and for investigating the effect of each contributing factor.

The current study also highlights the application of population-based biophysically detailed models of cardiac electrophysiology to simulate real patients within a virtual environment providing the possibility of applying such approaches towards personalised medicine and therapeutics. For example, with the use of such mechanistic modelling approaches in combination with infrequent clinical measurements, one can estimate when the plasma concentrations in an overdosed patient return to safe levels and also assess when the safety biomarkers (e.g. QTc) are expected to reach safe levels. This individual patient-centred assessment procedure could allow the medical staff to estimate the duration of hospitalisation, potentially replacing the current frequent blood sampling and clinical marker measurements to assess the recovery of the patient.

\section{CONCLUSIONS}

The results of this study indicate that considering only hERG ion channel inhibition of the parent drug, when predicting cardiotoxicity, may not provide reliable predictions. Where possible, the inclusion of active metabolite data and the influence of other ion channel currents should be considered for a better prediction of potential cardiac toxicity. Mechanistic modelling can help fill the current gaps in the quantitative translation of preclinical cardiac safety assessment to clinical toxicology. Population-based biophysically detailed models can potentially be used in personalised therapeutics, and the mathematical models based around the 'virtual twin' concept should be considered as one of the approaches towards such bespoke patient therapies. Further case studies with varying PK and PD characteristics are warranted to improve confidence in 


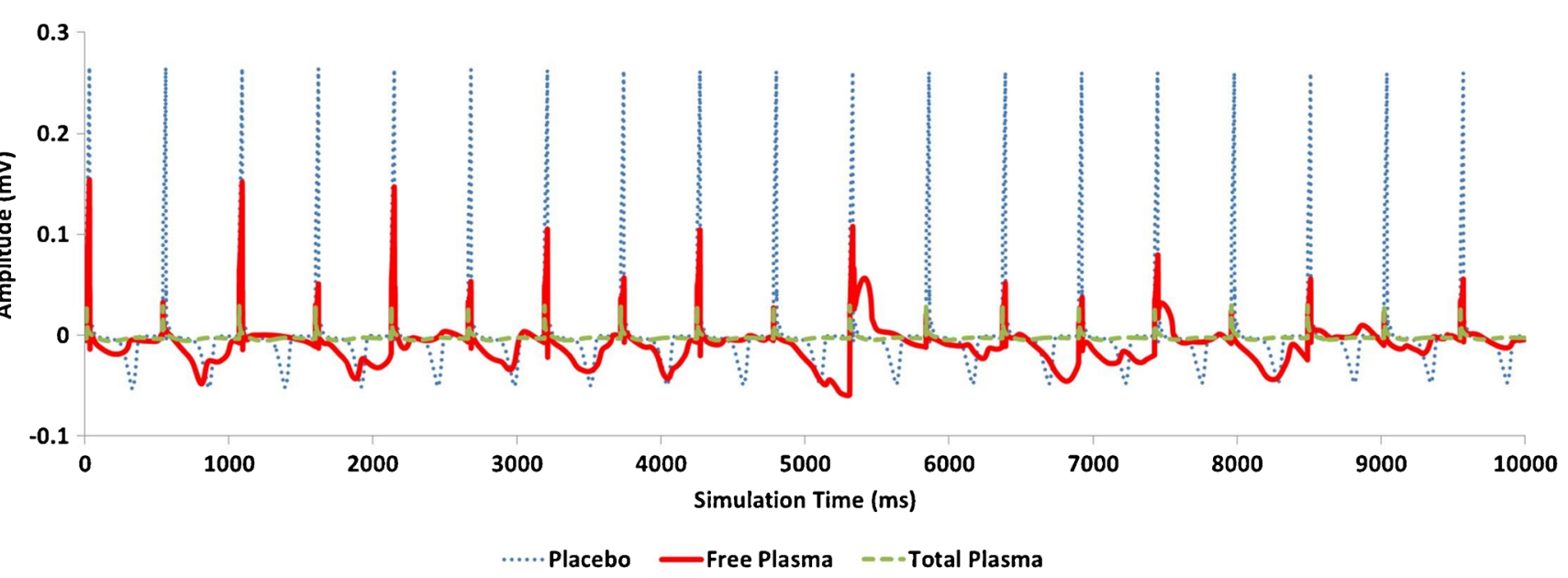

Fig. IV. Simulated pseudoECG for case III at exposure S3E1 with free and total plasma concentrations as operating concentrations

this approach and increase awareness of such modelling strategies in the quantitative translation of preclinical cardiac safety assessment to clinical situations.

\section{ACKNOWLEDGEMENTS}

Authors would like to thank Dr. Ruth Clayton for proofreading and editorial support and Ms. Eleanor Savill and Ms. Rosalie Bower for technical help in the preparation and submission of this manuscript. The Cardiac Safety Simulator is freely available, following completion of the relevant workshop, to approved members of academic institutions and other notfor-profit organisations for research and teaching purposes.

\section{AUTHORS' CONTRIBUTIONS}

SP and NP participated in the research design. NP conducted the experiments and performed the data analysis. $\mathrm{NP}, \mathrm{SP}, \mathrm{BW}$, and MJ contributed to the writing of the manuscript.

\section{COMPLIANCE WITH ETHICAL STANDARDS}

Conflict of Interest NP, SP, and MJ are employees of Simcyp Limited (A Certara Company) that provided the CSS software.

Open Access This article is distributed under the terms of the Creative Commons Attribution 4.0 International License (http://creativecommons.org/licenses/by/4.0/), which permits unrestricted use, distribution, and reproduction in any medium, provided you give appropriate credit to the original author(s) and the source, provide a link to the Creative Commons license, and indicate if changes were made.

\section{REFERENCES}

1. Friesen KJ, Bugden SC. The effectiveness and limitations of regulatory warnings for the safe prescribing of citalopram. Drug Healthc Patient Saf. 2015;7:139-45. https://doi.org/10.2147/ DHPS.S91046.

2. US Food and Drug Adminstration. FDA drug safety communication: abnormal heart rhythms associated with high doses of
Celexa (citalopram hydrobromide). Silver Spring, MD: US Food and Drug Adminstration; 2011. http://www.fda.gov/ Drugs/DrugSafety/ucm269086.htm.

3. US Food and Drug Adminstration. FDA drug safety communication: revised recommendations for Celexa (citalopram hydrobromide) related to a potential risk of abnormal heart rhythms with high doses. Silver Spring, MD: US Food and Drug Adminstration; 2012. https:// www.fda.gov/Drugs/DrugSafety/ucm297391.htm.

4. Overø K, Hojelse F. The unexpected preclinical finding-elucidation of dog toxicity-citalopram. In Excerpts from a workshop on the use of pharmacology studies in drug safety assessment - present situation and future perspectives: September 26-27, Stockholm, Sweden. Stockholm: Association of the Swedish Pharmeceutical Industry (Lakemedelsindustriforen.) (LIF); Uppsala: Medical Products Agency [Lakemedelsverket]; 1994. p. 113-6.

5. Rohrbacher J, Bex P, Gallacher DJ. Citalopram metabolites inhibit IKs and IKr differentially: is this a possible explanation for the sudden deaths in dogs? J Pharmacol Toxicol Meth. 2012;66(2):170. https://doi.org/10.1016/j.vascn.2012.08.040.

6. Witchel HJ, Pabbathi VK, Hofmann G, Paul AA, Hancox JC. Inhibitory actions of the selective serotonin re-uptake inhibitor citalopram on HERG and ventricular L-type calcium currents. FEBS Lett. 2002;512(1-3):59-66. https://doi.org/10.1016/S00145793(01)03320-8.

7. Hamplova-Peichlova J, Krusek J, Paclt I, Slavicek J, Lisa V, Vyskocil F. Citalopram inhibits L-type calcium channel current in rat cardiomyocytes in culture. Physiol Res. 2002;51(3):317-21.

8. Pacher P, Ungvari Z, Nanasi PP, Furst S, Kecskemeti V. Speculations on difference between tricyclic and selective serotonin reuptake inhibitor antidepressants on their cardiac effects. Is there any? Curr Med Chem. 1999;6(6):469-80.

9. Friberg LE, Isbister GK, Duffull SB. Pharmacokineticpharmacodynamic modelling of QT interval prolongation following citalopram overdoses. Br J Clin Pharmacol. 2006;61(2):177-90. https://doi.org/10.1111/j.1365 2125.2005.02546.x

10. Bird ST, Crentsil V, Temple R, Pinheiro S, Demczar D, Stone M. Cardiac safety concerns remain for citalopram at dosages above $40 \mathrm{mg} /$ day. Am J Psychiatry. 2014;171(1):17-9. https:// doi.org/10.1176/appi.ajp.2013.13070905.

11. Zivin K, Pfeiffer PN, Bohnert AS, Ganoczy D, Blow FC, Nallamothu BK, et al. Evaluation of the FDA warning against prescribing citalopram at doses exceeding $40 \mathrm{mg}$. Am J Psychiatry. 2013;170(6):642-50. https://doi.org/10.1176/ appi.ajp.2013.12030408.

12. Hutton LM, Cave AJ, St-Jean R, Banh HL. Should we be worried about QTc prolongation using citalopram? A review. J Pharm Pract. 2016;30(3):353-8. https://doi.org/10.1177/ 0897190015624862.

13. Polak S, Wisniowska B, Fijorek K, Glinka A, Mendyk A. In vitro-in vivo extrapolation of drug-induced proarrhythmia predictions at the population level. Drug Discov Today. 2014;19(3):275-81. https://doi.org/10.1016/j.drudis.2013.10.009. 
14. Wisniowska B, Polak S. Virtual clinical trial toward polytherapy safety assessment: combination of physiologically based pharmacokinetic/pharmacodynamic-based modeling and simulation approach with drug-drug interactions involving terfenadine as an example. J Pharm Sci. 2016;105(11):3415-24. https://doi.org/10.1016/j.xphs.2016.08.002.

15. Abbasi M, Small BG, Patel N, Jamei M, Polak S. Early assessment of proarrhythmic risk of drugs using the in vitro data and single-cell-based in silico models: proof of concept. Toxicol Mech Methods. 2017;27(2):88-99. https://doi.org/ 10.1080/15376516.2016.1256460.

16. Wisniowska B, Polak S. Am I or am I not proarrhythmic? Comparison of various classifications of drug TdP propensity. Drug Discov Today. 2017;22(1):10-6. https://doi.org/10.1016/ j.drudis.2016.09.027.

17. Colatsky T, Fermini B, Gintant G, Pierson JB, Sager P, Sekino Y, et al. The Comprehensive in Vitro Proarrhythmia Assay (CiPA) initiative-update on progress. J Pharmacol Toxicol Methods. 2016;81:15-20. https://doi.org/10.1016/ j.vascn.2016.06.002.

18. Crumb WJ Jr, Vicente J, Johannesen L, Strauss DG. An evaluation of 30 clinical drugs against the comprehensive in vitro proarrhythmia assay (CiPA) proposed ion channel panel. J Pharmacol Toxicol Methods. 2016;81:251-62.

19. Cavero I, Guillon JM, Ballet V, Clements M, Gerbeau JF, Holzgrefe H. Comprehensive in vitro Proarrhythmia Assay (CiPA): pending issues for successful validation and implementation. J Pharmacol Toxicol Methods. 2016;81:21-36. https:// doi.org/10.1016/j.vascn.2016.05.012.

20. Wisniowska B, Tylutki Z, Wyszogrodzka G, Polak S. Drug-drug interactions and QT prolongation as a commonly assessed cardiac effect-comprehensive overview of clinical trials. BMC. Pharmacol Toxicol. 2016;17:12.

21. Tucker GT, Rostami-Hodjegan A, Toon S, inventors; Systems and methods for predicting and adjusting the dosage of medicines in individual patients. US Patent 2016/0335412 A1 Filed Jan 27, 2014.

22. Segal NL, McGuire SA, Stohs JH. What virtual twins reveal about general intelligence and other behaviors. Pers Individ Dif. 2012;53(4):405-10. https://doi.org/10.1016/j.paid.2011.11.019.

23. Bedding A, Scott G, Brayshaw N, Leong L, Herrero-Martinez $\mathrm{E}$, Looby M, et al. Clinical trial simulations-an essential tool in drug development. The Association of the British Pharmaceutical Industry; 2014. http://www.abpi.org.uk/our-work/library/ industry/Documents/trial_design.pdf.

24. Hartmanshenn C, Scherholz M, Androulakis IP. Physiologicallybased pharmacokinetic models: approaches for enabling personalized medicine. J Pharmacokinet Pharmacodyn. 2016;43(5):481-504. https://doi.org/10.1007/s10928-016-9492-y.

25. Jamei M. Recent advances in development and application of physiologically-based pharmacokinetic (PBPK) models: a transition from academic curiosity to regulatory acceptance. Curr Pharmacol Rep. 2016;2(3):161-9. https://doi.org/10.1007/s40495016-0059-9.

26. Tucker GT. Personalized drug dosage-closing the loop. Pharm Res. 2017;34(8):1539-43. https://doi.org/10.1007/s11095-0162076-0.

27. ten Tusscher KH, Panfilov AV. Alternans and spiral breakup in a human ventricular tissue model. Am J Physiol Heart Circ Physiol. 2006;291(3):H1088-100. https://doi.org/10.1152/ ajpheart.00109.2006.

28. Polak S, Fijorek K. Inter-individual variability in the pre-clinical drug cardiotoxic safety assessment-analysis of the agecardiomyocytes electric capacitance dependence. J Cardiovasc Transl Res. 2012;5(3):321-32. https://doi.org/10.1007/s12265-0129357-8.
29. Polak S, Fijorek K, Glinka A, Wisniowska B, Mendyk A. Virtual population generator for human cardiomyocytes parameters: in silico drug cardiotoxicity assessment. Toxicol Mech Methods. 2012;22(1):31-40. https://doi.org/10.3109/ 15376516.2011.585477.

30. Liotier J, Coudoré F. Drug monitoring of a case of citalopram overdosage. Drug Chem Toxicol. 2011;34(4):420-3. https:// doi.org/10.3109/01480545.2011.566571.

31. Tarabar AF, Hoffman RS, Nelson L. Citalopram overdose: late presentation of torsades de pointes (TdP) with cardiac arrest. J Med Toxicol. 2008;4(2):101-5. https://doi.org/10.1007/ BF03160963.

32. Unterecker S, Warrings B, Deckert J, Pfuhlmann B. Correlation of QTc interval prolongation and serum level of citalopram after intoxication - a case report. Pharmacopsychiatry. 2012;45(1):30 4. https://doi.org/10.1055/s-0031-1286346.

33. Ji Y, Schaid DJ, Desta Z, Kubo M, Batzler AJ, Snyder K, et al. Citalopram and escitalopram plasma drug and metabolite concentrations: genome-wide associations. Br J Clin Pharmacol. 2014;78(2):373-83. https://doi.org/10.1111/bcp.12348.

34. Jamei M, Marciniak S, Edwards D, Wragg K, Feng K, Barnett A, et al. The Simcyp population based simulator: architecture, implementation, and quality assurance. In Silico Pharmacol. 2013;1(1):9. https://doi.org/10.1186/2193-9616-1-9.

35. Jamei M, Marciniak S, Feng K, Barnett A, Tucker G, RostamiHodjegan A. The Simcyp population-based ADME simulator. Expert Opin Drug Metab Toxicol. 2009;5(2):211-23. https:// doi.org/10.1517/17425250802691074.

36. Lobell M, Sivarajah V. In silico prediction of aqueous solubility, human plasma protein binding and volume of distribution of compounds from calculated $\mathrm{pKa}$ and $\mathrm{A} \log \mathrm{P} 98$ values. Mol Divers. 2003;7(1):69-87. https://doi.org/10.1023/ B:MODI.0000006562.93049.36.

37. Baumann P, Larsen F. The pharmacokinetics of citalopram. Rev Contemp Pharmaco. 1995;6:287-95.

38. Wisniowska B, Polak S. The role of interaction model in simulation of drug interactions and QT prolongation. Curr. Pharmacol Rep. 2016;2(6):339-44. https://doi.org/10.1007/ s40495-016-0075-9.

39. Fijorek K, Patel N, Klima L, Stolarz-Skrzypek K, KaweckaJaszcz K, Polak S. Age and gender dependent heart rate circadian model development and performance verification on the proarrhythmic drug case study. Theor Biol Med Model. 2013;10(1):7. https://doi.org/10.1186/1742-4682-10-7.

40. Fijorek K, Puskulluoglu M, Polak S. Circadian models of serum potassium, sodium, and calcium concentrations in healthy individuals and their application to cardiac electrophysiology simulations at individual level. Comput Math Methods Med. 2013;2013:429037. https://doi.org/10.1155/2013/429037.

41. Bazett HC. An analysis of the time-relations of electrocardiograms. Ann Noninvasive Electrocardiol. 1997;2(2):177-94. https://doi.org/10.1111/j.1542-474X.1997.tb00325.x.

42. Minematsu T, Ohtani H, Yamada Y, Sawada Y, Sato H, Iga T. Quantitative relationship between myocardial concentration of tacrolimus and QT prolongation in guinea pigs: pharmacokinetic/pharmacodynamic model incorporating a site of adverse effect. J Pharmacokinet Pharmacodyn. 2001;28(6):533-54. https://doi.org/10.1023/A:1014460404352.

43. Tylutki Z, Polak S. Plasma vs heart tissue concentration in humans-literature data analysis of drugs distribution. Biopharm Drug Dispos. 2015;36(6):337-51. https://doi.org/ 10.1002/bdd.1944.

44. Tylutki Z, Polak S. A four-compartment PBPK heart model accounting for cardiac metabolism-model development and application. Sci Rep. 2017;7:39494. https://doi.org/10.1038/ srep39494. 